\title{
Uso da cana-de-açúcar na alimentação de ruminantes ${ }^{1}$
}

\author{
Use of sugarcane in ruminant nutrition
}

\author{
SIQUEIRA, Gustavo Rezende ${ }^{2 *}$; ROTH, Marcella de Toledo Piza ${ }^{3}$; MORETTI, \\ Matheus Henrique ${ }^{3}$; BENATTI, João Marcos Beltrame ${ }^{3}$; RESENDE, Flávio Dutra de ${ }^{2}$
}

${ }^{1}$ Revisão apresentada no Congresso Brasileiro de Zootecnia (ZOOTEC 2011).

${ }^{2}$ Agência Paulista de Tecnologia dos Agronegócios, Departamento de Descentralização do Desenvolvimento, Colina, São Paulo, Brasil.

${ }^{3}$ Universidade Estadual Paulista, Faculdade de Ciências Agrárias e Veterinárias, Departamento de Zootecnia, Jaboticabal, São Paulo, Brasil

*Endereço para correspondência: siqueiragr@apta.sp.gov.br

\section{RESUMO}

Objetiva-se com essa revisão abordar os aspectos relevantes à utilização da cana-deaçúcar na alimentação de ruminantes. A canade-açúcar é uma forrageira que apresenta elevada produtividade de massa por área, o que representa a principal vantagem de sua utilização. Entretanto, o corte diário é um empecilho para sua adoção em muitas propriedades. Opções como o tratamento químico da cana-de-açúcar in natura ou a ensilagem são válidas, mas possuem limitações. A cana-de-açúcar sempre foi considerada uma forrageira de baixa qualidade nutricional. Nesta revisão serão tecidas considerações para interpretar essas limitações nutricionais com um novo aspecto. E por fim serão apresentados trabalhos científicos que mostram o potencial de uso da cana-de-açúcar como volumoso para ruminantes.

Palavras-chave: bovinos de corte, bovinos de leite, ensilagem, volumoso.

\section{SUMMARY}

The objective of this review is to highlight the important aspects of the usage of sugar cane to feed ruminants. Sugar cane is forage that presents high productivity body per area, meaning the main advantage of its usage. However, its daily cut accounts in hindrance. Chemical treatment of sugar cane in natura or silage are alternative options but there also limitations. Sugar cane is considered forage of low nutritional value. This review aims at bringing about new interpretations for these nutritional limitations considering new aspects. Finally, scientific works will be presented to demonstrate the potential usage of sugar cane as roughages.

Keywords: beef cattle, dairy cattle, ensiled, roughages.

\section{INTRODUÇÃO}

A cana-de-açúcar é considerada por muitos autores a opção forrageira de melhor desempenho bioeconômico para ser utilizada na alimentação de bovinos de corte e leite (NUSSIO et al., 2003; RESENDE et al., 2005; SIQUEIRA et al., 2008). Todavia, cabe ressaltar que há exceções, principalmente, em um país com proporções continentais como o Brasil.

Mesmo que para muitos autores, a cana apresente inúmeras vantagens como volumoso, há muitas recomendações para que esta não seja indicada como alimento para animais de bom potencial genético, pois apresenta baixo teor proteico e de minerais e fibra de 
baixíssima qualidade. Embora as considerações sobre sua limitações nutricionais sejam verdadeiras, precisam ser consideradas sob uma nova ótica.

Vários aspectos relacionados à escolha de variedades, manejo agronômico, colheita e picagem são negligenciados pelos produtores, o que leva ao insucesso do uso deste forrageiro. Outra questão são as formas de uso: normalmente a cana é colhida todos os dias, o que muitas vezes inviabiliza sua utilização, devido a entraves de logística. Esta revisão aborda as formas atuais do uso da cana-de-açúcar, tais como a ensilagem ou o tratamento químico.

$\mathrm{Na}$ comparação da cana com outras forrageiras, o que primeiro precisa ser elucidado é a necessidade de ajuste das dietas, para que haja uma comparação justa e adequada. Os estudos que apenas trocaram o volumoso de forma imprópria, na visão dos autores desta revisão, não apresentaram validação teórica e nem prática.

Esta revisão foi elaborada com a finalidade de discutir os aspectos, que no entendimento dos autores, são os mais relevantes da utilização da canade-açúcar, como recurso forrageiro para ruminantes.

\section{A ESCOLHA DA VARIEDADE}

A definição estratégica, na escolha de variedade de cana-de-açúcar, representa a possibilidade de uso desse volumoso, com qualidade adequada, durante todo o período de entressafra das pastagens. As variedades de cana são agrupadas em função da época de maturação, isto é, classificam-se em precoce, média e tardia. Fazendas pecuárias raramente utilizam o conceito de maturação para determinar sua colheita. Essa falha representa um dos motivos que pode promover redução no desempenho animal, pois, quando imatura, a forrageira apresenta baixa concentração de açúcares solúveis e alta concentração de fibra.

É recorrente na literatura a afirmação de que a cana é um volumoso de baixa qualidade, devido ao baixo teor de proteína bruta. E existem ainda tentativas de definir como parâmetro para o melhoramento da cana-de-açúcar, destinada à alimentação animal, o aumento daquele nutriente. Os autores do presente texto recomendam utilizar a variedade com o teor de proteína mais baixo que for encontrada. As explicações para essa questão serão elucidadas na próxima seção.

Alguns esforços têm sido realizados no sentido de desenvolver variedades de cana-de-açúcar com maior digestibilidade da fração fibrosa (LANDELL et al., 2002). Um bom exemplo foi o lançamento da variedade IAC-86-2480, considerada uma variedade específica para alimentação animal, devido à alta digestibilidade da fração fibrosa em relação às outras cultivares existentes, o que foi comprovado pelo estudo de Carvalho et al. (2010). Atualmente, esse programa de melhoramento genético também tem aconselhado o uso da variedade IACSP93-3046, pois esta apresenta alta digestibilidade da fibra e boa produção de massa.

A principal justificativa para a utilização da cana-de-açúcar é a elevada produção de massa por unidade de área (SIQUEIRA et al., 2008). Um bom parâmetro a ser considerado, na escolha de cultivares, é a produção de matéria seca digestível por hectare, pois tal parâmetro considera aspectos quantitativos e qualitativos.

Ao se trabalhar de forma conjunta os dados obtidos por Andrade et al. (2003) 
e Bonomo et al. (2009), observou-se que a relação entre produção de matéria digestível/hectare está mais relacionada à produção de matéria seca, do que à digestibilidade. Dessa forma, infere-se que a escolha das variedades, com anseios de melhoria da qualidade, não pode ser realizada em detrimento das características produtivas. Cabe ressaltar que no mercado há variedades que atendem aos quesitos quantiqualitativos para sua utilização na alimentação animal.

\section{ASPECTOS NUTRICIONAIS: LIMITAÇÕES E SUAS IMPLICAÇC̃ES}

O objetivo desta seção é elucidar as principais limitações nutricionais da cana-de-açúcar, mas simultaneamente esclarecer como tais restrições podem ser contornadas e consideradas benéficas.

O teor de proteína é considerado um dos maiores empecilhos para a adoção da cana como alimento volumoso para ruminantes. Os valores de proteína bruta variam de 1,91 a 3,81\% (ANDRADE et al., 2004; BONOMO et al., 2009). Realmente, a forrageira apresenta concentração de nitrogênio muito baixa, que pode ser comparada a do resíduo pós-colheita de semente de capimMarandu, que apresenta valores próximos a $3 \%$ de $\mathrm{PB}$, conforme constatado por Roth el al. (2010).

Por outro lado, é negligenciada sua capacidade de fixar carbono com baixa exigência em nitrogênio. Ao se comparar os resultados de dois estudos que avaliaram a resposta produtiva de milho e cana-de-açúcar, em função da dose de nitrogênio aplicada, tem-se o real do benefício desta: apresentar baixa concentração de nitrogênio (Figura 1).

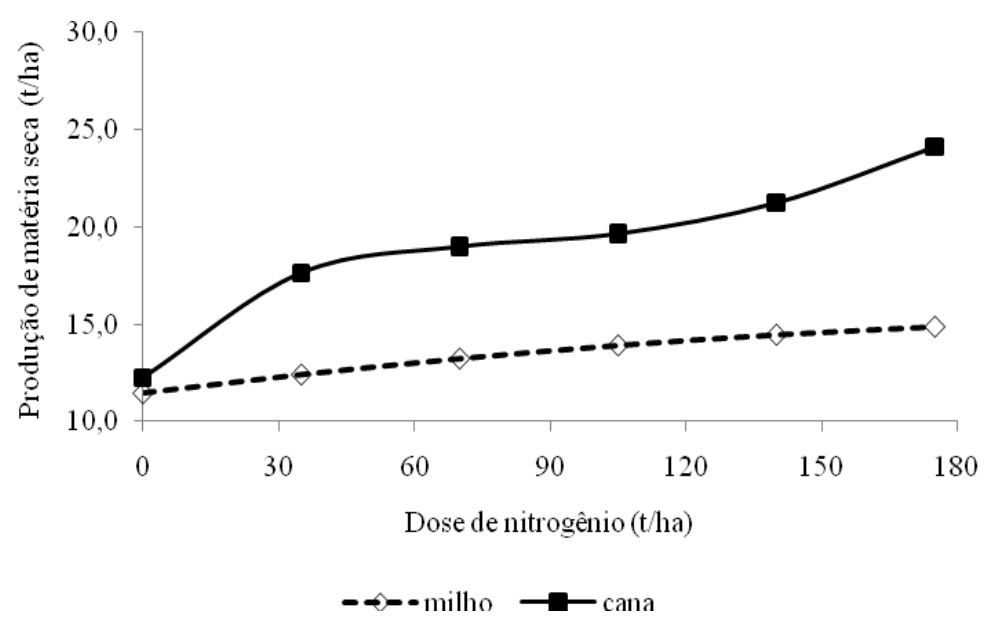

A dose de nitrogênio diz respeito a adubação de cobertura do milho, sendo que em todas as doses foram adicionados $36 \mathrm{~kg}$ de N/ha na semeadura Adaptado de Vitti et al. (2007) e Janssen (2009)

Figura 1. Resposta das plantas de milho e cana-de-açúcar a doses de nitrogênio 
O milho para a silagem foi produzido na região de Castro em sistemas de integração lavoura-pecuária em plantio direto (JANSSEN, 2009), e a cana foi avaliada em áreas de usinas no Estado de São Paulo (VITTI et al., 2007). Ressalta-se que, no caso da cana-deaçúcar, a massa refere-se à produção de colmos, o que segundo Carvalho et al. (2010) representa $80 \%$ da cana destinada à alimentação animal e que a produção constatada na maior dose de $\mathrm{N}$ está aquém das observadas nos estudos de Andrade et al. (2004) e Bonomo et al. (2009). Não faz parte do objetivo desta seção comparar volumosos, mas apenas mostrar que uma deficiência da cana-de-açúcar, na verdade, para os autores desta revisão constitui-se em uma grande vantagem.

Caso a melhoria qualitativa da forrageira fosse baseada no aumento do teor proteico, provavelmente, esta perderia sua principal vantagem, que é a produtividade de massa seca. Por isso um questionamento se impõe: qual seria o produtor capaz de adubar uma cultura que produz cerca de 30 toneladas de matéria seca em um único corte anual, se essa tivesse cerca 8 a $10 \%$ de proteína? E qual seria a eficiência da aplicação única de elevadas doses de $\mathrm{N}$ ? Outro ponto que merece ser discutido diz respeito à fibra da cana-de-açúcar. Muitos comentários (informações sem rigor científico) relatam de maneira errônea que esta apresenta alta porcentagem de fibra. $\mathrm{Na}$ verdade, apresenta baixa porcentagem de FDN, que normalmente varia de 40 a $50 \%$, quando colhida no momento adequado (AZEVÊDO et al., 2003; BONOMO et al., 2009). Porém, esta fibra é de baixa qualidade, o que resulta em efeito marcante no consumo voluntário dos animais.

A porcentagem da fração fibrosa indegradável da cana é elevada, chega a representar $60 \%$ da FDN (FERNANDES et al., 2003), enquanto que, em silagens de milho e sorgo, a porção indigestível da fibra é de 28 a $33 \%$ (PIRES et al., 2010). Essa maior proporção de fração indegradável, proporciona baixa digestibilidade da fração fibrosa, o que afeta a repleção ruminal, de modo a impactar negativamente no consumo dessa forrageira. Corrêa et al. (2003) atribuíram à redução na produção de leite de vacas holandesas, de 34,4 para $31,9 \mathrm{~kg}$ de leite/dia, quando estas foram alimentadas com cana-de-açúcar e comparadas às vacas alimentadas com silagem de milho, ao menor consumo de matéria seca (1,5kg de MS/vaca/dia).

Segundo os autores, esse menor consumo, possivelmente, foi ocasionado pela menor digestibilidade da FDN da cana $(23,1 \%)$, em comparação da silagem de milho (42\%). Outra observação interessante foi a redução do consumo de matéria seca com o prolongar do período de avaliação, o que não foi observado quando os animais foram alimentados com silagem de milho. Esse resultado sugere redução na taxa de passagem e aumento no tempo de retenção total, conforme foram observados por Magalhães et al. (2006) em outro experimento no qual avaliaram a substituição da silagem de milho por cana-de-açúcar.

Ao buscar determinar a variabilidade genética de cultivares de cana-deaçúcar, Carvalho et al. (2010) avaliaram os efeitos dos componentes da fração fibrosa sobre a digestibilidade da matéria seca e da fibra. Primeiramente, os autores identificaram que a FDN do colmo apresenta menor digestibilidade (11,9\%), quando comparada a da folha $(23,9 \%)$. Todavia o teor de FDN do colmo é mais baixo $(38,2 \%)$, que o das folhas $(68,7 \%)$. Esses autores não consideraram a palhada que, 
provavelmente, possui valores de FDN superiores a da folha.

Outra observação interessante, que convém mencionar, é que quando as variedades foram colhidas no começo da safra, a redução na relação FDN/POL foi determinante para o aumento da digestibilidade da matéria seca. Já em épocas com maior acúmulo de açúcar (setembro) a digestibilidade da FDN tem influência marcante na digestibilidade da matéria seca. E por fim constatou-se que a digestibilidade da FDN relaciona-se com a relação lignina/FDN e não com a concentração de lignina, FDN, POL ou FDN/POL. O que, segundo os autores, demonstra que a digestibilidade da fibra está relacionada com a qualidade e não com a quantidade desta fibra.

Fica evidente que a porção fibrosa da cana é um limitante da sua inclusão em dietas de ruminantes. As buscas por alternativas que aumentem a taxa de passagem da cana devem ser reforçadas. Uma alternativa é a melhoria da digestibilidade da fibra, via programas de melhoramento genético, contudo, esta não pode ser obtida com reflexo na redução de produção. Outro questionamento comparece: uma vez que as dificuldades operacionais relacionadas à colheita da cana-deaçúcar é um entrave para sua utilização, o quanto se pode melhorar a digestibilidade da fração fibrosa, sem que ocorra o tombamento do canavial? Outra forma de alterar a taxa de passagem se faz pela utilização de partículas com menor tamanho, contudo, no Brasil, são raros os estudos que envolvem resposta animal ao tamanho de partícula da cana. Santos (2010), realizou um trabalho que avaliava três tamanhos médios de partículas e concluiu que há um confundimento entre as respostas obtidas pelos diferentes tamanhos de partícula e a alteração na relação volumoso:concentrado das dietas, devido ao maior índice de seleção nas dietas com os maiores tamanhos de partículas. Todavia, os autores desta revisão acreditam que a redução no tamanho médio da partícula traz benefícios aos animais, por possivelmente elevar a taxa de passagem da dieta, mas essa hipótese precisa ser constatada cientificamente.

\section{MANEJO AGRONÔMICO VOLTADO A ALIMENTAÇÃO ANIMAL}

Raros são os estudos que avaliaram alterações no manejo agronômico na cultura da cana-de-açúcar, com objetivo de alterar seu valor nutricional e com foco na alimentação animal. A experimentação agronômica com a cana é uma linha de pesquisa bastante explorada, quando destinada ao setor sucroalcooleiro. Dessa forma, de maneira generalizada deve-se seguir as recomendações de plantio, manejo, adubação, controle de pragas e doenças conforme as idealizadas para produção de açúcar e etanol.

Um grande problema se nota quando a cana é reservada à alimentação animal, isso quer dizer que seu potencial produtivo é subutilizado, devido a não realização dos cuidados básicos com cultura. Pode-se atribuir que muitos insucessos na utilização dessa forrageira para alimentação animal são justificados pelo não atendimento mínimo das exigências da cultura e não nos aspectos nutricionais.

Em um estudo que avaliou o espaçamento de plantio sobre a produção da cana-deaçúcar, foi observada pela autora maior produtividade no tratamento que utilizou espaçamento de $0,90 \mathrm{~m} \quad(56,67 \mathrm{tMS} / \mathrm{ha})$ comparado a 1,3m (48,12tMS/ha) - 
(MURARO et al., 2011). Uma primeira constatação importante desse estudo, foi que o adensamento não afetou a produção, nesse caso, aumentou a produtividade. Tal aumento de produção está baseado na forma de plantio, pois a autora utilizou 15 gemas por metro linear nos dois espaçamentos, consequentemente, o número de perfilhos por metro linear não foi alterado e houve maior número de perfilhos por hectare no tratamento de $0,90 \mathrm{~m}$. Aos produtores, que possuem maquinário com elevada capacidade de colheita, esta pode ser um alternativa proveitosa, pois o único acréscimo no custo foi o maior número de mudas e horas/máquina para realizar a operação de sulcagem.

Todavia, na maioria das propriedades, as máquinas utilizadas para a colheita da cana-de-açúcar são as adquiridas para a colheita de culturas como milho e sorgo. Essas máquinas geralmente possuem uma capacidade inferior às projetadas para a colheita da cana, o que leva a sua rápida depreciação.

Uma possibilidade para aumentar a vida útil de colhedoras de forragem, específicas para a cana, é a redução da massa de forragem colhida por metro linear. Dessa forma, a adoção de espaçamentos menores como o sugerido por Muraro et al. (2011), ainda que se utilize a mesma quantidade de mudas por hectare, torna possível um canavial com produção semelhante por área, cuja massa por metro linear passa a ser inferior, o que facilita o processo de colheita por máquinas menores e de menor custo. Muraro et al. (2009) mostraram também que a redução no espaçamento de 1,3 para 0,9 não afetou a composição bromatológica da canade-açúcar fresca, nem ensilada.

Ainda, no que concerne à colheita da cana, Nussio et al. (2006) demonstram que mesmo que seja reduzida a vida útil do canavial, a colheita mecanizada diminui significativamente o custo de produção do volumoso. Quando esta é realizada por colhedoras de forragens, há perdas de 8 a 10 toneladas de massa verde/hectare, devido ao resíduo "toco" deixado pela máquina (RODRIGUES et al., 2008; SCHOGOR et al., 2009).

Além dessa perda considerável, o setor produtivo inquietava-se com $\mathrm{O}$ destino desse resíduo. As primeiras recomendações, baseadas nos conceitos do corte manual, era de proceder a retirada desse resíduo pós-colheita com o uso de podões, com seu rebaixamento rente ao solo. Essa técnica praticamente inviabilizaria o processo mecânico, pois oneraria muito a operação, devido ao aumento na mão-de-obra. Em propriedades, onde a cana era utilizada para grandes rebanhos, por exemplo, roçadoras hidráulicas foram empregadas para o rebaixamento daquele resíduo. Essa técnica considerava a hipótese de que se o resíduo pós-colheita permanecesse na área, ocorreriam brotações aéreas e tanto a produção, como a colheita do próximo ciclo ficariam comprometidos. Para compreender essas questões estudos, como o de Rodrigues et al. (2008) e Schogor (2008), foram realizados. No trabalho de Rodrigues et al. (2008), foi constatado aumento da produtividade, quando o resíduo pós-colheita não foi retirado, e atribuiu-se esse efeito a um possível aporte de carboidratos para o estímulo à brotação da planta. Já Schogor (2008) observou que após a colheita mecanizada, sem rebaixamento do resíduo, ocorre a emissão de perfilhos aéreos, mas estes apresentam sobrevivência de até 90 dias. Constatouse também que o tipo de colheita, manual, mecanizada e mecanizada com rebaixamento, não alterou o número de perfilhos basais, nem a produção. 
A única ressalva para a recomendação do não rebaixamento é que os dois estudos utilizaram a mesma variedade IAC 86-2480 e foram realizados em locais próximos. Atualmente, é de conhecimento dos autores deste texto que muitas propriedades não têm realizado o rebaixamento do resíduo pós-colheita e não têm observado problemas na rebrota, porém estudos que considerem diferenças climáticas e variedades de cana-de-açúcar são necessários.

FORMAS DE USO DA CANA-DEAÇÚCAR PARA ALIMENTAÇÃO ANIMAL

A grande adoção da cana como forma de volumoso suplementar para a seca baseia-se na facilidade e tradição de cultivo e, sobretudo, por constituir-se em opção competitiva, quando comparada à outras fontes de volumosos (NUSSIO, et al., 2003). De acordo com os mesmo autores, seu uso in natura é tradicional e de amplo conhecimento dos produtores, entretanto, demanda mão-de-obra diária para cortes, despalhamento, picagem, transporte, logo, estabelece limitação logística/operacional quando se pretende suplementar rebanhos de maior porte.

Dessa forma, a possibilidade de conservação desse material para fornecimento posterior aos animais permitiria melhor logística para sua utilização e, consequentemente, redução dos custos associados ao corte diário. A seguir serão discutidas as formas alternativas ao uso da forrageira in natura.

\section{TRATAMENTO QUÍMICO DA CANA-DE-AÇÚCAR IN NATURA}

Para contornar a necessidade do corte diário, foi proposta a utilização de compostos alcalinos como controladores da ação de micro-organismos no processo de deterioração da cana-de-açúcar após a picagem da forragem (OLIVEIRA et al., 2008). Além da conservação do material, o uso de agentes alcalinos, como a cal virgem $(\mathrm{CaO})$ e cal hidratada $\left[\mathrm{Ca}(\mathrm{OH})_{2}\right]$, segundo Van Soest (1994), atua sobre as ligações covalentes do tipo éster entre a lignina e a parede celular, de modo a quebrá-las e a aumentar a solubilidade da fração fibrosa.

Ao trabalharem com esse mesmo contexto químico, Mota et al. (2010), verificaram redução nos teores de fibra em detergente neutro (FDN) e hemicelulose da cana hidrolisada em comparação à cana in natura. Nesse experimento, a redução nas frações resultou da solubilização parcial dos constituintes da parede celular, pois o efeito dos produtos alcalinos normalmente ocorre pela solubilização parcial da hemicelulose e pela expansão da celulose, o que facilitaria o ataque dos micro-organismos do rúmen à parede celular.

Além dos benefícios sobre a fração fibrosa, foram comprovados por Domingues et al. (2011) os benefícios da utilização da cal virgem sobre estabilidade aeróbia da cana-de-açúcar in natura após a picagem. Os autores verificaram controle da população de leveduras, dos valores de $\mathrm{pH}$ e da temperatura. Concluiu-se que a dose de $0,5 \%$ de cal virgem é a mais indicada para o controle das alterações da estabilidade aeróbia da forrageira.

Decerto existe efeito benéfico dos agentes alcalinos sobre a solubilização 
da fibra e sobre o controle de microorganismos indesejáveis na conservação da forragem, após a picagem. Todavia, foi comprovado por Santos et al. (2009), que durante a exposição aeróbia da cana após a picagem, há consumo de carboidratos solúveis. Constatou-se redução média de 10 unidades percentuais de carboidratos solúveis nas primeiras seis horas de exposição, independente da dose de cal utilizada. $\mathrm{O}$ fato de adicionar a cal virgem à canade-açúcar proporcionou consumo instantâneo de carboidratos solúveis, ou seja, após 12 horas de exposição ao ar, o conteúdo de carboidratos solúveis é reduzido a $8-10 \%$ da MS, em uma forragem que apresentava cerca $20-27 \%$ da MS. Essa redução é ocasionada pela respiração celular, ocorrida após o corte da planta e acelerada com o processo de picagem, o que implica perdas de matéria seca. As vantagens obtidas com o aumento da solubilidade da fibra são compensadas negativamente pelas perdas de carboidratos solúveis, de modo a proporcionar ao processo apenas vantagens logísticas, caso estas existam.

Ao avaliar o efeito do tratamento com agentes alcalinos sobre o desempenho de bovinos confinados, normalmente encontra-se efeito benéfico sobre a digestibilidade das frações fibrosas (MOTA et al., 2010), mas observa-se redução no consumo de matéria seca e no desempenho animal (MORAES et a., 2008; PINA et al., 2011), ou nos melhores casos não se observa efeito maléfico (DOMINGUES, 2009). Dessa forma, a ideia de que o tratamento químico da cana in natura resulta em aumento na digestibilidade é válida, porém não parece ter efeito positivo no desempenho animal. Ainda que haja uma vantagem operacional da não realização de cortes diários, há de se considerar o custo da mão-de-obra para a mistura do agente alcalino com a cana-de-açúcar, o que seria inviável em rebanhos de médio e grande porte.

\section{ENSILAGEM DA CANA-DE-AÇÚCAR}

A ensilagem da cana-de-açúcar foi proposta a fim de, ao mesmo tempo, contornar as dificuldades operacionais na condução do corte diário e promover uma concentração de atividades que propiciem o aumento da eficiência do uso de mão-de-obra e maquinários, aliado à redução do risco de incêndios acidentais. Outras questões, como: a rebrota uniforme do talhão e a realização de práticas agronômicas podem ser consideradas vantagens da adoção da prática da ensilagem em comparação ao corte diário.

No entanto, na fermentação da cana ocorre intensa atividade de leveduras epífitas, que convertem açúcar a $\mathrm{CO}_{2}$, água e etanol (BERNARDES et al., 2007). Essa conversão acarreta a redução do valor nutritivo e elevadas perdas durante a estocagem, a diminuição no teor de carboidratos solúveis e o aumento relativo no teor de FDN das silagens (SIQUEIRA et al., 2007a).

A maioria dos fungos e das leveduras necessita de oxigênio para seu crescimento, todavia, algumas espécies de leveduras se desenvolvem em condições anaeróbias e podem manter altas populações nessas condições. A fermentação dos açúcares alimenta essa multiplicação, de modo a fazê-las dominar o processo fermentativo em silagens de cana, em que, na maioria das vezes, não são inibidas pela redução do $\mathrm{pH}$ no alimento e possuem a habilidade de crescer em intervalos de 2 a 8 (WALKER, 1998; BERNARDES et al., 2007). 
Devido às perdas inerentes a este processo de ensilagem, provenientes da ação de leveduras, tem sido constante a indicação do uso de aditivos para reduzir essas perdas (SIQUEIRA et al., 2007b; PEDROSO et al., 2007; ROTH et al., 2010a). Talvez, a cana-de-açúcar seja a única cultura que requer, de forma contundente, o uso de aditivos na ensilagem.

\section{ADITIVOS NA ENSILAGEM DA CANA-DE-AÇÚCAR}

Vários aditivos foram testados nos últimos anos com intuito de controlar a ação das leveduras na ensilagem da cana-de-açúcar. Os resultados mais promissores foram encontrados quando utilizado óxido de cálcio (BALIERO NETO et al., 2007; SANTOS et al., 2008; AMARAL et al., 2009; ROTH et al., 2010a) e Lactobacillus buchneri (PEDROSO et al., 2007; SQUEIRA al., 2007ab; ÁVILA et al., 2009).

A utilização do óxido de cálcio tem apresentado maior repetibilidade na redução das perdas de matéria seca, provavelmente, por este ser um aditivo químico e ser menos dependente das condições do meio para sua ação. Roth et al. (2008), indicaram que doses de 0,5 a $1,0 \%$ são eficientes em reduzir as perdas de matéria seca.

O L. buchneri foi colocado por Nussio \& Schmidt (2004), como possível aditivo de sucesso a ser utilizado na ensilagem da cana, devido aos resultados obtidos nas pesquisas até o presente momento. Schmidt (2008) aponta que L. buchneri foi o aditivo mais pesquisado na ensilagem da canade-açúcar (25 trabalhos), principalmente pelos bons resultados obtidos por Pedroso et al. (2006), que teve parte dos dados divulgados na publicação da tese de Pedroso em 2003. Schmidt (2008) mostra que a variabilidade no padrão de resposta do $L$. buchneri parece ser superior à assistida para outros aditivos (ureia, óxido de cálcio, benzoato de sódio), por se tratar de um organismo vivo, dependente de uma série de fatores, como substrato, umidade, população inicial entre outros.

De forma geral, existe na literatura uma massa crítica de dados, que permitem a indicação dos referidos aditivos, quando o objetivo é o controle de perdas durante o armazenamento. Já em relação ao desempenho animal, o número de trabalhos é reduzido. No que respeita ao $L$. buchneri, os estudos indicam respostas nulas (SIQUEIRA, 2009), a positivas (PEDROSO et al., 2006), para esse aditivo dificilmente há redução de desempenho. Enquanto em relação ao óxido de cálcio, existem trabalhos que mostram efeito negativo (MARI, 2008) e outros positivos (ROTH et al., 2010b), o que permite inferir-se que para se indicar, asseguradamente, o uso de óxido de cálcio mais pesquisas são necessárias.

\section{RESPOSTA ANIMAL AO USO DA CANA-DE-AÇÚCAR}

A utilização da cana-de-açúcar como recurso forrageiro no Brasil, geralmente, está associada a pequenos produtores, com rebanhos de baixo potencial genético, cujo fornecimento é feito, em vários casos, de forma inadequada, isto é, aquém do ideal para o atendimento das "exigências" dos animais.

Segundo Magalhães et al. (2004), a maioria dos trabalhos conduzidos até aquele momento, que a utilizavam como recurso volumoso em dietas para vacas leiteiras, limitou seu uso para animais de baixa produção. 
$\mathrm{O}$ fato que tenha levado a esse descrédito da cana deve-se, talvez, aos próprios estudos que objetivavam substituir a silagem de milho por esse volumoso, sem o adequado balanceamento das rações (MARI, 2008). Segundo Nussio et al. (2006), os desequilíbrios na produção de leite, gerado por vacas alimentadas com rações compostas de cana-de-açúcar, provavelmente se devem mais ao desbalanceamento de nutriente do que a uma característica intrínseca a essa fonte de forragem. Os autores afirmam ainda que a combinação adequada de ingredientes, cuja finalidade deve ser corrigir as deficiências nutricionais do volumoso, é fator preponderante para o sucesso de sua utilização.

Pode-se dizer que, nos anos 2000, a comunidade científica aumentou seu nível de conhecimento sobre a formulação de dietas baseadas na canade-açúcar e trabalhos que utilizam animais de elevada produção foram realizados (CORRÊA et al. 2003; MAGALHÃES et al., 2004; MENDONÇA et al., 2004; COSTA et al., 2005; QUEIROZ et al., 2008). Com a realização destes trabalhos ficou demonstrado que esta pode ser utilizada na alimentação de vacas com produção superior a $20 \mathrm{~kg}$ de leite/dia. O maior exemplo do potencial do uso dessa forrageira cana foi observado no trabalho de Corrêa et al. (2003), que alimentaram vacas de leite com a cana, único volumoso disponibilizado, e constataram produção de $31,9 \mathrm{~kg}$ de leite/dia.

Há de se considerar que o uso desse volumoso na alimentação de vacas de média a alta produção deve ser realizado com cuidado, pois o aumento da participação da cana na dieta implica redução de consumo (MAGALHÃES et al., 2004; COSTA et al., 2005). Corrêa et al. (2003) observaram redução no consumo de matéria seca com a alimentação prolongada da cana, fato não constatado, quando os animais foram alimentados com silagem de milho.

Com base nos resultados obtidos nos experimentos supracitados e em outros experimentos (MAGALHÃES et al., 2004; COSTA et al., 2005; MENDONÇA et al., 2004), a inclusão da cana na dieta de vacas leiteiras de média a alta produção, deve ser feita até em níveis máximos de $40 \%$ da matéria seca, devido à depleção no consumo e no desempenho das vacas. A limitação no consumo encontra-se relacionada à repleção ruminal total, devido à maior retenção ruminal e à menor taxa de passagem em dietas com esse volumoso, ocorrências prioritariamente regidas pela FDN indigestível (VALADARES FILHO et al., 2008).

NUSSIO et al. (2006) em simulação de desempenho de vacas alimentadas com fontes de cana-de-açúcar, que continham alteração no teor de FDN, encontraram redução de aproximadamente $30 \%$ na produção de leite, quando o volumoso passou, supostamente, de 44\% de FDN, na MS, para $64 \%$ FDN, na MS. Os autores concluíram que a cada duas unidades no teor de FDN da cana, a produção de leite reduziu em um $\mathrm{kg}$ de leite/vaca/dia.

A utilização de cana-de-açúcar para bovinos de corte está associada, principalmente, à animais confinados, na qual serve como alimento alternativo, em decorrência de seu menor custo. Entretanto, suas limitações nutricionais devem ser consideradas e corrigidas para permitir desempenhos similares aos obtidos com outras fontes de volumosos de melhor valor nutricional (PINTO et al., 2010). Qualquer que seja a comparação realizada entre volumosos, faz-se necessário o adequado ajuste das dietas, pois a sua 
mera substituição, sem considerar as características, deve ser evitada (SIQUEIRA et al., 2008).

Conforme discutido no item anterior, a parede celular altamente lignificada da cana reduz a digestibilidade da fibra, o que causa a repleção ruminal e, consequentemente, redução em consumo, fato também constatado em dietas para animais de corte. Valadares Filho et al. (2008) realizaram um metaanálise, com o objetivo de entender o efeito do aumento da inclusão daquele volumoso sobre o consumo $\mathrm{e} o$ desempenho de bovinos de corte confinados. Ficou evidente que o aumento da inclusão da cana, na dieta, proporciona decréscimo no consumo e no desempenho. Todavia, fica claro também que esta, quando utilizada de forma correta, com animais que apresentem potencial de ganho, proporcionam desempenho adequado. Atualmente, ganhos em peso da ordem de 1,200 a $1,500 \mathrm{~kg} /$ dia são observados em trabalhos que a utilizaram como volumoso único (FERNANDES et al., 2007; OLIVEIRA et al., 2009; PINTO et al., 2010).

Como a maior participação de concentrado nas dietas tem sido prática comum, no Brasil, o uso da cana-deaçúcar como fonte de volumoso cresce novamente. Segundo Nussio et al. (2006), dados não oficiais apontam que cerca de $35 \%$ dos confinamentos utilizam-na como volumoso. Como no caso de gado de corte, o uso desta está associado a confinamentos, o que demonstra o interesse, por parte dos produtores, pela utilização de silagem de cana-de-açúcar, no lugar da cana in natura.

Ao considerar que a concentração de FDN na cana-de-açúcar é o principal limitante do desempenho e que sua ensilagem aumenta proporcionalmente o teor de FDN, devido às perdas de carboidratos solúveis, o esperado seria que o desempenho de bovinos alimentados com tal silagem fosse inferior, quando comparado ao de animais alimentados com a forragem in natura. Todavia, os trabalhos realizados recentemente não têm constatado essa diferença (QUEIROZ et al., 2008; MARI, 2008; SIQUEIRA, 2009), além desse fato, tem-se constatado desempenho semelhante a outras fontes de volumosos como a silagem de milho, desde que as devidas correções da dieta sejam realizadas (QUEIROZ et al., 2008; SIQUEIRA, 2009; ROMAN et al., 2011).

Queiroz et al. (2008) compararam a utilização da silagem de cana-de-açúcar com a in natura, ambas com participação de $40 \%$ na dieta e com a silagem de milho, com participação de $50 \%$, na alimentação de vacas leiteiras, com média de produtividade de $25 \mathrm{~kg}$ leite/dia. Não foi observada diferença na produção de leite em função dos tratamentos avaliados. Tal resultado evidencia que se os ajustes nutricionais forem realizados, e que a relação volumoso:concentrado seja resultado da dieta formulada e não o alvo na pré-programação, a silagem de cana apresenta potencial para ser utilizada na alimentação de vacas leiteiras de boa produção.

$\mathrm{Na}$ alimentação de gado de corte em confinamento de terminação, Roman et al. (2011) compararam a utilização de silagem de milho e silagem de cana-deaçúcar. Utilizaram-se 285 animais em confinamento de baias coletivas, com 19 animais por baia, ou seja, um desenho experimental que proporciona grande respaldo a avaliação. A inclusão da silagem de cana foi de $35 \%$ na dieta e da silagem de milho de $43 \%$. Foi observado maior consumo pelos animais alimentados com silagem de milho $(10,51 \mathrm{kgMS} /$ dia $)$ em comparação 
aos alimentados com silagem de canade-açúcar (10,08kgMS/dia). Contudo o desempenho não apresentou diferença significativa $(\mathrm{P}=0,27)$ : o observado em ganho de peso foi de $1,445 \mathrm{e}$ $1,475 \mathrm{~kg} / \mathrm{dia}$ pelos animais alimentados com silagem de cana-de-açúcar e de milho, respectivamente.

Dessa forma, fica evidenciado que a silagem desta pode ser utilizada também no confinamento de bovinos de corte, com bons resultados de desempenho animal. Fato relevante na utilização dessas silagens foi abordado nos estudos de Schmidt (2006) e de Mari (2008), nos quais foram verificado que os modelos nutricionais subestimam o desempenho e superestimam o consumo animal, em aproximadamente 10\%, a principal justificativa está baseada na falta de contabilização dos compostos voláteis como fonte energética.

A escolha da variedade precisa primeiro ser baseada na produtividade do canavial e, em segundo plano, nas variações bromatológicas, ainda que se tenha conhecimento dos efeitos da fibra sobre o desempenho, a principal justificativa para o uso da cana-deaçúcar é a produtividade.

Limitações como baixas concentrações de nitrogênio e minerais que são exaustivamente colocadas na literatura devem ser repensadas, pois apresentam a oportunidade de elevada produção de massa com baixa exigência em minerais via adubação.

A busca por alternativas que acelerem a saída da porção fibrosa do ambiente ruminal devem ser perseguidas, quer seja pela redução da FDN indigestível, quer seja pelo aumento da taxa de passagem, uma vez que há evidencias claras da limitação de consumo de bovinos alimentados com cana-deaçúcar.

Algumas práticas agronômicas, como a redução do espaçamento entre linhas e não necessidade de retirada do resíduo pós-colheita mecânica, são atividades que podem contribuir para a redução de custos e o aumento da viabilidade do uso dos equipamentos.

O tratamento da cana-de-açúcar com agentes alcalinos, embora aumente a digestibilidade da fração fibrosa, em alguns casos imprime perdas de conteúdo celular, devido à respiração. $\mathrm{Na}$ maioria das vezes o desempenho animal tem sido prejudicado, quando animais são alimentados com cana-deaçúcar tratada com agentes alcalinos.

A ensilagem constitui-se em alternativa para o armazenamento da cana, mas requer o uso de aditivos para o controle da ação de leveduras, dos quais os indicados são o óxido de cálcio e o $L$. buchneri.

O uso da cana-de-açúcar, desde que, contornadas as limitações nutricionais, com os ajustes pertinentes nas dietas, pode ser uma realidade para animais de alta performance, tanto para produção de leite quanto para a produção de carne.

\section{AGRADECIMENTOS}

Os autores agradecem a todos os membros do Grupo de Estudos em Produção de Ruminantes (GEPROR) pelo auxílio na elaboração desta revisão e no planejamento, execução $e$ elaboração dos experimentos com utilização de cana-de-açúcar para alimentação animal.

\section{REFERÊNCIAS}

AMARAL, R.C.; PIRES, A.V.; SUSIN, I.; NUSSIO, L.G.; MENDES, C.Q.; GASTALDELLO JUNIOR, A.L. Canade-açúcar ensilada com ou sem aditivos químicos: fermentação e composição química. Revista Brasileira de

Zootecnia, v.38, n.8, p.1413-1421, 2009. 
ANDRADE, J.B.; FERRARI JÚNIOR, E.; POSSENTI, R.A.; OTSUK, I.P.; ZIMBACK, L.; LANDELL,M.G.A. Seleção de 39 variedades de cana-deaçúcar para alimentação animal.

Brazilian Journal of Veterinary Research and Animal Science, v.40, n.4, p.287-296, 2003.

ANDRADE, J.B.; FERRARI JUNIOR, E.; POSSENTI, R.A.; OTSUK, I.P.; ZIMBACK, L.; LANDELL, M.G.A. Composição química de genótipos de cana-de-açúcar em duas idades, para fins de nutrição animal. Bragantia, v.63, n.3, p.341-349, 2004.

ÁVILA, C.L.S.; PINTO, J.C.; FIGUEIREDO, H.C.P.; SCHWAN, R.F. Effects of na indigenous and a commercial Lactobacillus buchneri strain on quality of sugar cane silage. Grass and Forage Science, v. 64, n.1, p.384-394, 2009.

AZEVÊDO, J.A.G.; PEREIRA, J.C.; CARNEIRO, P.C.S.; QUEIROZ, A.C.; BARBOSA, M.H.P.; FERNANDES, A.M.; RENNÓ, F.P. Avaliação da divergência nutricional de variedades de cana-de-açúcar (Saccharum spp.L.).

Revista Brasileira de Zootecnia, v.32, n.6, p.1431-1442, 2003.

BALIEIRO NETO, G.; SIQUEIRA, G.R.; REIS, R.A.; NOGUEIRA, J.R.; ROTH, M.T.P.; ROTH, A.P.T.P. Óxido de cálcio como aditivo na ensilagem de cana-de-açúcar. Revista Brasileira de Zootecnia, v.36, n.5, p.1231-1239, 2007.

BERNARDES, T.F.; REIS, R.A.; SIQUEIRA, G.R.; Berchielli, T.T.; COAN, R.M. Avaliação da queima e da adição de milho desintegrado com palha e sabugo na ensilagem de cana-deaçúcar. Revista Brasileira de

Zootecnia, v.36, n.2, p.269-275, 2007.
BONOMO, P.; CARDOSO, C.M.M.; PEDREIRA, M.S.; SANTOS, C.C.; PIRES, A.J.V.; SILVA, F.F. Potencial forrageiro de variedades de cana-deaçúcar para alimentação de ruminantes. Acta Scientiarium. Animal Sciences, v.31, n.1, p.53-59, 2009.

CARVALHO, M.V.; RODRIGUES, P.H.M.; LIMA, M.L.P.; ANJOS, I.A.; LANDELL, M.G.A.; SANTOS, M.V.; SILVA, L.F.P. Composição bromatológica e digestibilidade de cana-de-açúcar colhida em duas épocas do ano. Brazilian Journal of Veterinary Research and Animal Science, v.47, n.4, p.298-306, 2010.

CORRÊA, C.E.S.; PEREIRA, M.N.; OLIVEIRA, S.G.; RAMOS, M.H. Performance of Holstein cows fed sugarcane or corn silages of different grain textures. Scientia Agricola, v.60, p.221-229, 2003.

COSTA, M.G.; CAMPOS, J.M.S.; VALADARES FILHO, S.C.; VALADARES, R.F.D.; MENDONÇA, S.S.; SOUZA, D.P.; TEIXEIRA, M.P.

Desempenho produtivo de vacas leiteiras alimentadas com diferentes proporções de cana-de-açúcar e concentrado ou silagem de milho na dieta. Revista Brasileira de

Zootecnia, v.34, n.6, p.2437-2445, 2005.

DOMINGUES, F.N. Cana-de-açúcar hidolisada com doses crescentes de cal virgem e tempos de exposição ao ar para a alimentação de bovinos. 2009. 108f. Tese (Doutorado em Zootecnia) - Faculdade de Ciências Agrárias e Veterinárias - Universidade Estadual Paulista, Jaboticabal. 
DOMINGUES, F.N.; OLIVEIRA, M.D.S.; SIQUEIRA, G.R.; ROTH, A.P.T.P.; SANTOS, J. MOTA, D.A. Estabilidade aeróbia, pH e dinâmica de desenvolvimento de microrganismos da cana-de-açúcar in natura hidrolisada com cal virgem. Revista Brasileira de Zootecnia, v.40, n.4, p.715-719, 2011.

FERNANDES, A.M.; QUEIROZ, A.C.; PEREIRA, J.C.; LANA, R.P.; BARBOSA, M.H.P.; FONSECA, D.M.; DETMANN, E.; CABRAL, L.S.; PEREIRA, E.S.; VITTORI, A. Composição químico-bromatológica de variedades de cana-de-açúcar (Saccharum spp.L.) com diferentes ciclos de produção (precoce e intermediário) em três idades de colheita. Revista Brasileira de Zootecnia, v.32, n.4, p.977-985, 2003.

FERNANDES, A.R.M; SAMPAIO, A.A.M.; HENRIQUE, W.; PERECIN, D.; OLIVEIRA, E.A.; TÚLLIO, R.R. Avaliação econômica e desempenho de machos e fêmeas Canchim em confinamento alimentados com dietas à base de silagem de milho e concentrado ou cana-de-açúcar e concentrado contendo grãos de girassol. Revista Brasileira de Zootecnia, v.36, n.4, p.855-864, 2007.

JANSSEN, H.P. Adubação nitrogenada para rendimento de milho silagem em sucessão ao azevém pastejado, pré-secado e cobertura em sistemas integrados de produção. 2009. 92f. Dissertação (Mestrado em Fitotecnia) Universidade Federal do Paraná, Curitiba, 2009.
LANDELL, M.G.A.; CAMPANA, M.P.; RODRIGUES, A.A.; BATISTA, L.A.R.; FIGUEIREDO, P.; SILVA, M.A.; BIDOIA, M.A.P.; ROSSETO, R.; MARTINS, A.L.; KANTHACK, R.A.O.; CAVICHIOLI, J.C.; VASCONCELLOS, A.C.M.; XAVIER, M.A. A variedade IAC862480 como nova opção de cana-deaçúcar para fins forrageiros: manejo de produção e uso na alimentação animal. Campinas: Instituto Agronomico, 2002. 39p. (Bletim tecnico IAC, 193).

MAGALHÃES, A.L.R.; CAMPOS, J.M.S.; CABRAL, L.S.; MELLO, R.; FREITAS, J.A.; TORRES, R.A.; VALADARES FILHO, S.C.; ASSIS, A.J. Cana-de-açúcar em substituição à silagem de milho em dietas para vacas em lactação: parâmetros digestivos e ruminais. Revista Brasileira de Zootecnia, v.35, n.2, p.591-599, 2006.

MAGALHÃES, A.L.R.; CAMPOS, J.M.S.; VALADARES FILHO, S.C.; TORRES, R.A.; MENDES NETO, J.; ASSIS, A.J. Cana-de-açúcar em substituição à silagem de milho em dietas para vacas em lactação: desempenho e viabilidade econômica. Revista Brasileira de Zootecnia, v.33, n.5, p.1292-1302, 2004.

MARI, L. Desempenho de bovinos de corte alimentados com rações contendo cana-de-açúcar (Saccharum officinarum L.) fresca ou ensilada e o padrão de fermentação e a estabilidade aeróbica das silagens aditivadas. 2008. 315p. Tese (Doutorado em Agronomia) - Escola Superior de Agricultura Luiz de Queiroz, Piracicaba. 
Rev. Bras. Saúde Prod. Anim., Salvador, v.13, n.4, p.991-1008 out/dez., 2012 http://www.rbspa.ufba.br ISSN 15199940

MENDONÇA, S.S.; CAMPOS, J.M.S.;

VALADARES FILHO, S.C.;

VALADARES, R.F.D.; SOARES,

C.A.; LANA, R.P.; QUEIROZ, A.C.;

ASSIS, A.J.; PEREIRA, M.L.A.

Consumo, digestibilidade aparente, produção e composição do leite e variáveis ruminais em vacas leiteiras alimentadas com dietas à base de canade-açúcar. Revista Brasileira de

Zootecnia, v.33, n.2, p.481-492, 2004.

MORAES, K.A.K.; VALADARES FILHO, S.C.; MORAES, E.B.K.; LEÃO, M.I.; VALADARES, R.F.D.; PEREIRA, O.G.; SOLÉRO, B.P. Canade-açúcar tratada com óxido de cálcio fornecida com diferentes níveis de concentrado para novilhas de corte em confinamento. Revista Brasileira de Zootecnia, v.37, n.7, p.1293-1300, 2008.

MOTA, D.A.; OLIVEIRA, M.D.S.; DOMINGUES, F.N.; MANZI, G.M.; FERREIRA, D.S.; SANTOS, J.

Hidrólise da cana-de-açúcar com cal virgem ou cal hidratada. Revista

Brasileira de Zootecnia, v.39, n.6, p.1186-1190, 2010.

MURARO, G.B. ROSSI Jr., P.; SCHOGOR, A.L.B. Produção de biomassa de cana-de-açúcar em dois espaçamentos e duas frequências de corte. Ciência e Agrotecnologia, v.35, n.1, p.131-136, 2011.

MURARO, G.B.; ROSSI JUNIOR, P.; OLIVEIRA, V.C.; GRANZOTTO, P.M.C.; SCHOGOR, A.L.B. Efeito da idade de corte sobre a composição bromatológica e as características de cana-de-açúcar plantada em dois espaçamentos e três idades de corte.

Revista Brasileira de Zootecnia, v.38, n.8, p.1525-1531, 2009.
NUSSIO, L.G.; ROMANELLI, T.L.; ZOPOLLATTO, M. Tomada de decisão na escolha de volumosos suplementares para bovinos de corte em confinamento. In: SIMPÓSIO GOIANO SOBRE MANEJO E NUTRIÇÃO DE BOVINOS DE CORTE E LEITE, 5, 2003, Campinas. Anais... Campinas: CBNA, 2003. p.114.

NUSSIO, L.G.; SCHMIDT, P. Tecnologia de produção e valor alimentício de silagens de cana-deaçúcar. In: SIMPÓSIO SOBRE PRODUÇÃO E UTILIZAÇÃO DE FORRAGENS CONSERVADAS, 2, 2004, Maringa. Anais... Maringá: UEM/CCA/DZO, 2004. p.1-33.

NUSSIO, L.G.; SCHMIDT, P.; SCHOGOR, A.L.B.; MARI, L.J. Cana-de-açúcar como alimento para bovinos. In: SIMPÓSIO SOBRE MANEJO ESTRATÉGICO DA PASTAGEM, 3, 2006, Viçosa. Anais... Viçosa: FUNERB, 2006. p. 277-328.

OLIVEIRA, E.A.; SAMPAIO, A.A.M.; FERNANDES, A.R.M.; HENRIQUE, W.; OLIVEIRA, R.V.; RIBEIRO, G.M. Desempenho e características de carcaça de tourinhos Nelore e Canchim terminados em confinamento recebendo dietas com cana-de-açúcar e dois níveis de concentrado. Revista Brasileira de

Zootecnia, v.38, n.12, p.2465-2472, 2009.

OLIVEIRA, M.D.S.; BARBOSA, J.C.; MOTA, D.A.; ANDRADE, A.T. Efeito da hidrólise com cal virgem sobre a composição bromatológica da cana-de-açúcar. Veterinária Notícias, v.14, n.1, p.19-27, 2008. 
Rev. Bras. Saúde Prod. Anim., Salvador, v.13, n.4, p.991-1008 out/dez., 2012 http://www.rbspa.ufba.br ISSN 15199940

PEDROSO, A.F.; NUSSIO, L.G.;

BARIONI JÚNIOR, W.;

RODRIGUES, A.A.; LOURES,

D.R.S.; CAMPOS, F.; RIBEIRO, J.L.;

MARI, L.; ZOPOLLATTO, M.;

JUNQUEIRA, M.; SCHMIDT, P.;

PAZIANI, S.F.; HORII, J.

Performance of Holstein heifers fed sugarcane silages treated with urea, sodium benzoate or Lactobacillus

buchneri. Pesquisa Agropecuária

Brasileira, v.41, n.4, p.649-654, 2006.

PEDROSO, A.F.; NUSSIO, L.G.; LOURES, D.R.S; PAZIANI, S.F.; IGARASI, M.S.; COELHO, R.M.; HORII, J.; RODRIGUES, A.A. Efeito do tratamento com aditivos químicos e inoculantes bacterianos nas perdas e na qualidade de silagens de cana-deaçúcar. Revista Brasileira de

Zootecnia, v.36, n.3, p.558-564, 2007.

PINA, D.S.; VALADARES FILHO, S.C.; TEDESCHI, L.O.; BARBOSA, A.M.; AZEVÊDO, J.A.; VALADARES, R.F.D.; SOUZA, N.K.P.; FONSECA, M.A. Níveis de inclusão e tempo de exposição da cana-de-açúcar ao óxido de cálcio sobre parâmetros digestivos e o desempenho de novilhas Nelore. Revista Brasileira de Zootecnia, v.40, n.3, p.648-656, 2011.

PINTO, A.P.; ABRAHÃO, J.J.S.; MARQUES, J.A.; NASCIMENTO, W.G.; PEROTTO, D.; LUGÃO, S.M.B. Desempenho e características de carcaça de tourinhos mestiços em confinamento com dietas à base de cana-de-açúcar em substituição à silagem de milho. Revista Brasileira de Zootecnia, v.39, n.1, p.198-203, 2010.
PIRES, A.J.V.; REIS, R.A.;

CARVALHO, G.G.P.; SIQUEIRA, G.R.; BERNARDES, T.F.; RUGGIERI, A.C.; ROTH, M.T.P. Degradabilidade ruminal da matéria seca, da proteína bruta e da fração fibrosa de silagens de milho, sorgo e de Brachiaria brizantha. Arquivo Brasileiro de Medicina Veterinária e Zootecnia, v.62, n.2, p.391-400, 2010.

QUEIROZ, O.M.; NUSSIO, L.G.; SCHMIDT, P.; RIBEIRO, J.L.; SANTOS, M.V.; ZOPOLLATTO, M. Silagem de cana-de-açúcar comparada a fontes tradicionais de volumosos suplementares no desempenho de vacas de alta produção. Revista Brasileira de Zootecnia, v.37, n.2, p.358-365, 2008.

RESENDE, F.D.; SIGNORETTI, R.D.; COAN, R.M.; SIQUEIRA, G.R. Terminação de bovinos de corte com ênfase na utilização de alimentos conservados. In: REIS, R.A.; SIQUEIRA, G.R.; BERTIPAGLIA, L.M.A. (Eds).

Volumosos na produção de ruminantes. Jaboticabal: Funep, 2005. p.83-104.

RODRIGUES, A.R.C.; ROMAN, J.; SIQUEIRA, G.R.; FERREIRA, L.H.; SALOMÃO, T.; RESENDE, F.D.

Produção de massa verde ensilável de cana-de-açúcar após diferentes manejos da porção remanescente da colheita mecanizada. In: REUNIÃO ANUAL DA SOCIEDADE BRASILEIRA DE ZOOTECNIA, 45, 2008, Lavras. Anais... Lavras: Sociedade Brasileira de Zootecnia, 2008.

ROMAM, J.; JOBIM, C.C.; RESENDE, F.D.; SIQUEIRA, G.R.; FARIA, M.H.; OLIVEIRA NETO, R.A. Performance of finishing beef cattle fed different diets containing whole-crop maize silage or sugarcane silage. Revista Brasileira de Zootecnia, v.40, n.3, p.682-689, 2011. 
ROTH, A.P.T.P.; REIS, R.A.;

SIQUEIRA, G.R.; RESENDE, F.D.;

MORETTI, M.H.; FERREIRA, L.H.

Desempenho de novilhos Nelore

confinados recebendo dietas com silagens

de cana-de-açúcar. In: REUNIÃO

ANUAL DA SOCIEDADE

BRASILEIRA DE ZOOTECNIA, 47,

2010, Salvador. Anais... Salvador:

Sociedade Brasileira de Zootecnia, 2010b.

ROTH, A.P.T.P.; REIS, R.A.; SIQUEIRA, G.R.; ROTH, M.T.P.; RESENDE, F.D.; MONTEIRO, R.R.

Sugarcane silage production treated with additives at different times post burning.

Revista Brasileira de Zootecnia, v.39, n.1, p.88-96, 2010a.

ROTH, A.P.T.P.; REIS, R.A.; SIQUEIRA, G.R.; BERNARDES, T.F.; RESENDE, F.D.; MONTEIRO, R.R. Perdas durante o processo fermentativo e estabilidade aeróbia de silagens de canade-açúcar crua e queimdada com doses de cal. In: REUNIÃO ANUAL DA SOCIEDADE BRASILEIRA DE ZOOTECNIA, 45, 2008, Lavras. Anais... Lavras: Sociedade Brasileira de Zootecnia, 2008.

ROTH, M.T.P.; REIS, R.A.; RESENDE, F.D.; SIQUEIRA, G.R.; PIRES, A.J.V.; BERTIPAGLIA, L.M.A. Chemical treatment of post-harvest Marandu grass seed residues with different moisture contents. Revista Brasileira de Zootecnia, v.39, n.3, p.479-486, 2010.

SANTOS, M.C.; NUSSIO, L.G.; MOURÃO, G.B.; SCHMIDT, P.; MARI, L.J.; RIBEIRO, J.L. Influência da utilização de aditivos químicos no perfil da fermentação, no valor nutritivo e nas perdas de silagens de cana-de-açúcar.

Revista Brasileira de Zootecnia, v.37, p.1555-1563, n.9, 2008.
SANTOS, M.C.; NUSSIO, L.G.; MOURÃO, G.B.; SCHMIDT, P.; MARI, L.J.; RIBEIRO, J.L.; QUEIROZ, O.C.M.; ZOPOLLATTO, M.; SOUSA, D.P.; SARTURI, J.O.; TOLEDO FILHO, S.C. Nutritive value of sugarcane silage treated with chemical additives. Scientia Agricola, v.66, n.2, p.159-163, 2009.

SANTOS, V.P. Tamanho de partículas da cana-de-açúcar in natura na alimentação de vacas e cabras em lactação. 2010. 121f. Tese (Doutorado em Ciência Animal e Pastagens) - Universidade de São Paulo, Escola Superior de Agricultura, Piracicaba.

SCHMIDT, P. Aditivos químicos e biológicos no tratamento de cana-deaçúcar para alimentação de bovinos. In: JOBIM, C.C.; CECATO, U.; CANTO, M.W. (Eds) Produção e utilização de forragens conservadas. Maringá: Masson, 2008. p.117-152.

\section{SCHMIDT, P. Perdas fermentativas} na ensilagem, parâmetros digestivos $e$ desempenho de bovinos de corte alimentados com rações contendo silagens de cana-de-açúcar. 2006. 228p. Tese (Doutorado em Agronomia) - Universidade de São Paulo, Escola Superior de Agricultura, Piracicaba.

\section{SCHOGOR, A.L.B. Avaliação} agronômica da cana-de-açúcar submetida a métodos de colheita para produção animal. 2008. 165f.

Dissertação (Mestrado em Agronomia:

Ciência Animal e Pastagens) Universidade de São Paulo, Escola Superior de Agricultura, Piracicaba.

SCHOGOR, A.L.B.; NUSSIO, L.G.; MOURÃO, G.B.; MURARO, G.B.; SARTURI, J.O.; MATOS, B.C. Perdas das frações de cana-de-açúcar 
submetida a diversos métodos de colheita. Revista Brasileira de

Zootecnia, v.38, n.8, p.1443-1450, 2009.

SIQUEIRA, G.R. Aditivos na silagem de cana-de-açúcar "in natura" ou queimada. 2009, 107f Tese (Doutorado em Zootecnia) - Universidade Estadual Paulista, Faculadade de Ciências Agrárias e Veterinárias, Jaboticabal.

SIQUEIRA, G.R.; REIS, R.A.; SCHOCKEN-ITURRINO, R.P.; BERNARDES, T.F.; PIRES, A.J.V.; ROTH, M.T.P.; ROTH, A.P.T.P. Associação entre aditivos químicos e bacterianos na ensilagem de cana-deaçúcar. Revista Brasileira de Zootecnia, v.36, n.4, p.789-798, 2007a.

SIQUEIRA, G.R.; REIS, R.A.; SCHOCKEN-ITURRINO, R.P.; PIRES, A.J.V.; BERNARDES, T.F.;

AMARAL, R.C. Perdas de silagens de cana-de-açúcar tratadas com aditivos químicos e bacterianos. Revista Brasileira de Zootecnia, v.36, n.6, p.2000-2009, 2007b (suplemento).

SIQUEIRA, G.R.; RESENDE, F.D.; REIS, R. A.; ROMAN, J.; BERNARDES, T.F.. Uso estratégico de forragens conservadas em sistemas de produção de carne. In: JOBIM, C.C.; CECATO, U.; CANTO, M.W. (Eds) Produção e utilização de forragens conservadas. Maringá: Masson, 2008. p.41-89.
VALADARES FILHO, S.C.; MARCONDES, M.I.; CHIZZOTTI, M.L.; BENEDETI, P.D.B.; SILVA, L.F.C. Otimização de dietas à base de cana-de-açúcar. In: SIMPÓSIO DE PRODUÇÃO DE GADO DE CORTE, 6, . Viçosa: Universidade Federal de Viçosa, 2008. p.121-182.

VAN SOEST, P.J. Nutritional ecology of the ruminant. 2.ed. Ithaca: Cornell University Press, 1994. 476p.

VITTI, A.C.; TRIVELIN, P.C.O.; GAVA, G.J.C.; PENATTI, C.P.; BOLOGNA, I.R.; FARONI, C.E.; FRANCO, H.C.J. Produtividade da cana-de-açúcar relacionada ao nitrogênio residual da adubação e do sistema radicular. Pesquisa Agropecuária Brasileira, v.42, n.2, p.249-256, 2007.

WALKER, G. M. Yeast physiology and biotechnology. London: Wiley Editorial Offices, 1998. 350p.

Data de recebimento: 10/11/2011 Data de aprovação: 09/11/2012 